\title{
Contexto institucional de referência e governança de redes: estudo em arranjos produtivos locais do estado do Paraná
}

\author{
Marcos de Castro \\ Universidade Estadual do Centro-Oeste \\ Sandro Aparecido Gonçalves \\ Universidade Federal do Paraná
}

Reconhecendo a diversidade de atores que compõem as redes interorganizacionais, este estudo adota a perspectiva institucional e uma concepção de ambiente em que distintos grupos de atores podem perceber de forma diferente o mesmo contexto institucional. Diante disso, o estudo se propõe a investigar como o compartilhamento dos valores do contexto institucional de referência se relaciona com a configuração da governança em três arranjos produtivos locais (APLs). Os resultados apontaram diferenças em termos de origem das pressões ambientais percebidas, evidenciando que o compartilhamento de valores referentes à cooperação afeta positivamente a configuração da governança. Assim, a principal contribuição do estudo diz respeito à forma com que os atores se organizam no contexto dos arranjos produtivos, pois parece ser fruto das relações locais, independentemente do nível do contexto em que se referencia. Isso permitiu evidenciar que são as interações no nível local que permitem que o conceito de APL ganhe concretude.

Palavras-chave: contexto institucional; governança; cooperação; competição; arranjos produtivos locais.

Contexto institucional de referencia y gobernanza de redes: estudio de arreglos productivos locales del estado de Paraná

Reconociendo la diversidad de actores que componen las redes interorganizacionales, este estudio adopta la perspectiva institucional y una concepción de ambiente en que diferentes grupos de actores pueden percibir de manera diferente el mismo contexto institucional. De ese modo, el estudio se propone investigar cómo el intercambio de los valores del contexto institucional de referencia se relaciona con la configuración de la gobernanza en tres arreglos productivos locales. Los resultados señalaron diferencias en la fuente de las presiones ambientales percibidas, lo que demuestra que compartir valores relativos a la cooperación afecta positivamente a la configuración de la gobernanza. Así, la principal

DOI: http://dx.doi.org/10.1590/0034-76121764

Artigo recebido em 30 out. 2013 e aceito em 21 maio 2014.

Rev. Adm. Pública - Rio de Janeiro 48(5):1281-1304, set./out. 2014 
contribución del estudio se refiere a la forma en que los actores se organizan en el contexto de los arreglos productivos, pues parece ser el resultado de relaciones locales, sin tener en cuenta el nivel del contexto en lo cual se referencia. Esto posibilitó demostrar que son las interacciones en el nivel local que permiten que el concepto de arreglos productivos locales gane concreción.

Palabras clave: contexto institucional; gobernanza; cooperación; competición; arreglos productivos locales.

Institutional context of reference and governance network: study in local productive arrangements of Paraná state

Recognizing the diversity of actors in the interorganizational network, this study adopts the institutional perspective and a conception of environment in which different groups of actors may perceive differently the same institutional context. Therefore, the study investigates how the sharing of the values of the reference institutional context relates to the governance setting in three local productive arrangements (LPAs). The results showed differences concerning the origin environmental pressures perceived, which highlights that the sharing of values about cooperation affects positively the governance setting. Therefore, the main contribution of the study is about the way that the actors organize themselves in the context of productive arrangements, as it seems to be result of the local relations, regardless the context level in which is referred. This fact allowed to show that the interactions in local level are the ones that enable the concept of LPA to gain concreteness.

KEYWords: institutional context; governance; cooperation; competition; local productive arrangements.

\section{Introdução}

O olhar sobre as redes envolve considerar elementos ambientais no sentido de que se permita incluir categorias de natureza social e institucional, reconhecendo que o comportamento dos atores no contexto das redes interorganizacionais é afetado por aspectos institucionais de caráter regulativo, normativo e cultural-cognitivo (Scott, 2008). Isso implica adotar uma perspectiva institucional para o tema das redes e uma concepção de ambiente em termos de fenômenos objetivos, mas sujeitos a diferentes interpretações por parte dos atores, ou seja, implica reconhecer que um conjunto tangível de fatores externos tem seu significado organizacional subjetivamente estabelecido. Portanto, atores enquanto indivíduos, grupos e organizações podem perceber de forma diferente o mesmo contexto institucional. Consequentemente, isso pode resultar em ações diversas na dinâmica do relacionamento entre organização e ambiente (Crubellate e Machado-da-Silva, 1998). Nessa concepção, as organizações tratam o ambiente tomando por base suas interpretações que se efetivam a partir das informações apreendidas por seus membros, o que pode resultar na atribuição de diferentes significados aos mesmos estímulos externos (Machado-da-Silva e Fonseca, 1996, 1999). Além disso, o argumento relacionado com o contexto institucional torna essa consideração ainda mais complexa, quando se consideram suas dimensões e níveis. As dimensões são representadas pelo ambiente técnico 
e pelo ambiente institucional (Dimaggio e Powell, 1983; Scott, 1992), e os seus quatro níveis local, regional, nacional e internacional (Machado-da-Silva e Fonseca, 1996).

No campo empírico, durante a década de 2000 o estado do Paraná passou por um intenso processo de disseminação do conceito de APL, que compreendeu essencialmente a identificação de regiões produtivas para o desenvolvimento de ações de apoio envolvendo, também, intensa articulação entre atores em várias esferas, sejam locais, estaduais e nacionais (Ipardes, 2006). Tem-se, assim, um contexto em que se identificam pelo menos dois grupos de atores: aqueles que propõem a adoção do conceito de APL no interior dos arranjos e as empresas que integram cada arranjo.

Reconhecendo a diversidade de atores que integram os arranjos, considera-se que a adoção da perspectiva institucional para a análise do sistema de governança de um APL, por meio da noção de contexto institucional, permite se considerar a diversidade de papéis que compõem esse modelo de arranjo interorganizacional entre aqueles que estabelecem o modelo de governança e aqueles que são objeto de tais ações, mesmo tendo em conta que, em muitos casos, os atores atuem nos dois papéis devido à característica essencial do empreendimento cooperativo.

Basicamente se assume o pressuposto de que o contexto institucional tomado como referência para as ações de governança não necessariamente é compartilhado com os demais atores de uma mesma rede interorganizacional. Assim, considerando que o contexto institucional pode ser interpretado diferentemente pelos atores que propõem o modelo de APL em relação aos demais atores que integram o arranjo, surge a necessidade de investigar se tais diferenças ou correspondências se relacionam ou não com a efetividade do sistema de governança do APL (Gonçalves, 2007; Guarido Filho e Machado-da-Silva, 2001; Machado-da-Silva e Barbosa, 2002; Machado-da-Silva e Fonseca, 1996, 1999; Machado-da-Silva e Fernandes, 1998; Scott, 1987).

Diante dessas breves considerações, o presente estudo se direciona à compreensão das redes por meio da adoção de uma noção contextualizada dos APLs selecionados para a pesquisa, reconhecendo a importância de se articular a literatura de redes e relacionamentos interorganizacionais conjuntamente com a teoria institucional.

\section{Referencial teórico}

\subsection{Abordagem institucionalista}

A evolução na noção de ambiente organizacional é resultado, em parte, da contribuição da teoria institucional. Na visão dos institucionalistas, a relação entre organização e ambiente ocorre por meio da conformação ou da aceitação de padrões decorrentes da interação dos elementos ambientais, em que se incluem também as relações interorganizacionais. Assim, as organizações estão inseridas em um ambiente constituído de regras, crenças e valores, que são criados e consolidados por meio da interação social. Como consequência, a sua sobrevivência 
depende da capacidade de se conformar às orientações coletivamente compartilhadas, cuja permanente sustentação contribui para o êxito das ações organizacionais. Portanto, diante das mesmas prescrições ambientais, as organizações ainda competem pelo alcance da legitimidade no ambiente, o que as torna homogêneas ou isomórficas em suas práticas e estruturas (Dimaggio e Powell, 1983; Machado-da-Silva e Fonseca, 1996, 1999; Meyer e Rowan, 1977; Scott, 1987, 2008; Scott e Meyer, 1991).

Nessa perspectiva, a organização é tida como um sistema aberto também no plano cognitivo, cujas categorias e variáveis tomadas como relevantes para o entendimento do ambiente são, em alguma medida, influenciadas pelo contexto e pela história do próprio ambiente no qual a organização se insere. O pressuposto é o de que o ambiente pode ser mais adequadamente compreendido quando visualizado em termos de fenômenos objetivos, cujo significado dos elementos que compõem o ambiente é intersubjetivamente estabelecido pelos atores que integram as organizações (Gonçalves, 2007).

Para Scott (2008), o relacionamento entre organizações e ambiente pode ser mais bem compreendido a partir de uma estrutura analítica constituída por elementos de caráter regulativo, normativo e cultural-cognitivo, os quais formam os pilares que sustentam as instituições e operam em múltiplos níveis de análise. No pilar regulativo, impera a lógica de cálculo utilitário de custo-benefício na qual a ênfase é concedida aos aspectos regulativos das instituições, que constrangem e regulam o comportamento por meio de regras, monitoramento e sanções, recompensas e punições por meio de processos formais e informais. Considerando que as bases para a legitimidade consistem em regras, organizações legítimas seriam aquelas estabelecidas de acordo com os relevantes requerimentos legais. As manifestações da estrutura institucional regulativa são mais fáceis de serem observadas, pois normalmente se expressam por elementos explícitos formais e coercitivos (Scott, 2008).

Já o pilar normativo adota uma lógica de conformidade orientada por uma dimensão moralmente fundamentada no contexto social. A preocupação básica é o comportamento internalizado como padrão de conduta apropriada, considerando a construção de padrões para que estruturas ou comportamentos possam ser avaliados e comparados. Ao reconhecer o papel de valores e expectativas do grupo, é especificado como as coisas devem ser feitas, definindo significados legítimos para as ações, restringindo a escolha dos atores. Ao mesmo tempo que normas especificam como as coisas devem ser feitas e, usualmente, limitam o comportamento das organizações, mas também providenciando estabilidade e significado para o comportamento social (Scott, 2008).

Por sua vez, o pilar cognitivo tende à compreensão dos processos de mediação entre o mundo externo de estímulo-resposta do indivíduo via mecanismos que têm origem em um conjunto de representações simbólicas acerca do mundo. Assim, a compreensão ou a explicação de alguma ação exige a consideração de condições objetivas, bem como a interpretação subjetiva do ator (Scott, 2008).

As bases do pilar cognitivo são encontradas no estudo de Berger e Luckmann (2009). Os autores apresentam uma abordagem que considera um contexto cultural mais amplo, que se sobrepõe a aspectos subjetivos e enfatiza um processo de interação social que cons- 
titui as bases do processo de institucionalização no qual a criação de um conjunto de crenças e conhecimentos compartilhados dá origem a uma realidade socialmente construída. Conforme esses autores, instituições não são representadas somente por designações verbais e objetos físicos, mas também pressupõem que a realidade intersubjetiva emerge das interações sociais.

A noção de realidade socialmente construída do pilar cognitivo coloca a interpretação como um elemento mediador em função dos valores e das crenças subjacentes ao cálculo da ação, e da relação que se estabelece entre a cognição dos membros organizacionais e o ambiente (Gonçalves, 2007). Diante das possíveis alternativas existentes da variabilidade de possíveis interpretações de uma situação específica, encontra-se o conceito de esquemas interpretativos, que pode ser definido como o conjunto de crenças, valores e ideias que proporciona ordem e coerência às estruturas e aos sistemas em uma organização (Greenwood e Hinnings, 1988; Machado-da-Silva e Fonseca, 1999).

Nessa visão cognitiva da ação, o pressuposto fundamental é que existe um conjunto de crenças e valores comuns que permeia as visões e as interpretações individuais e representa um sistema cognitivo compartilhado, possibilitando, assim, que se fale em cognição do grupo ou da organização. Na visão de Greenwood e Hinings (1988), os esquemas interpretativos configuram, segundo a natureza ampla dos propósitos organizacionais e sua missão, os princípios apropriados de organização e os critérios de avaliação de desempenho. Possuem, portanto, papel fundamental no delineamento das ações organizacionais, uma vez que implicam uma visão de mundo, base para as ações, e interferem na formulação de tais ações por meio dos vieses cognitivos (Gonçalves, 2007; Machado-da-Silva e Fonseca,1999).

Isso leva a considerar que as pressões ambientais de caráter institucional e técnicas são complementares, não se configurando como dimensões opostas, mas constituintes de um mesmo contexto institucional (Powell, 1991). Scott e Meyer (1991) acrescentam que se deve considerar que os ambientes técnicos e institucionais coexistem e não devem ser tratados como mutuamente exclusivos. No centro dessa questão conceitual, encontra-se a distinção inicial entre ambiente técnico e ambiente institucional de Scott e Meyer (1991:123):

Technical environments are those in which a product or service is produced and exchanged in a market such that organizations are rewarded for effective and efficient control of their production systems. (...) Institutional environments are (...) those characterized by the elaboration of rules and requirements to which individual organizations must conform if they are to receive support and legitimacy.

Os ambientes técnicos são os espaços de competição sob a ótica econômica, em que a dinâmica de funcionamento ocorre por meio da troca de bens ou serviços, de forma que as organizações que dele fazem parte são avaliadas pelo trabalho realizado de maneira tecnicamente eficiente. Nesse sentido, o controle ambiental é exercido em termos de padrões de quantidade e qualidade, moldando as organizações por meio de processos isomórficos (Dimaggio e Powell, 1983; Machado-da-Silva e Fonseca, 1999; Scott e Meyer, 1991). Para Scott (1992), o ambiente técnico se mostra um conceito amplamente estudado, de forma 
que sua definição e operacionalização parecem estar consolidadas permitindo um razoável consenso no que diz respeito às dimensões que o compõem, resumidas pelos aspectos de incerteza e dependência.

Já os ambientes institucionais são caracterizados pela elaboração e difusão de regras e procedimentos que proporcionam legitimidade e suporte contextual às organizações. Nesse caso, o controle ambiental se dá pela adequação da forma organizacional às pressões sociais resultando, também, em isomorfismo. Assim, as condições de incerteza levam as organizações a se sujeitarem às exigências governamentais, copiarem estruturas e práticas ou implementarem medidas genericamente aceitas em redes profissionais (Dimaggio e Powell, 1983; Machado-da-Silva e Fonseca, 1999; Scott e Meyer, 1991).

A análise dos fenômenos organizacionais, além da necessidade de considerar o ambiente técnico e institucional, pode se revelar estrutural e simbolicamente diferenciada de acordo com o setor empresarial e apresentar uma conotação diversa ao se levarem em conta os diferentes níveis do contexto institucional (Machado-da-Silva e Barbosa, 2002). Diante disso, Machado-da-Silva e Fonseca (1996) argumentam que o nível de visualização ambiental da organização pode ser de escopo local, regional, nacional ou internacional, compondo, assim, o seu contexto institucional de referência. Portanto, o nível de análise contextual envolve tanto características do ambiente técnico quanto do institucional, pois cada organização se orienta pelo contexto institucional no nível que mais se coaduna com a sua trajetória e, portanto, com sua lógica interior.

\subsection{Governança de redes}

A utilização da concepção geral sobre governança no contexto das redes interorganizacionais implica adaptações conceituais decorrentes das especificidades que tornam as redes distintas da organização individual. Dado que as redes se caracterizam por atores que atuam conjuntamente para o alcance de benefícios coletivos, a governança em redes interorganizacionais se diferencia, primeiramente, pelo fato de que os atores governados são outras organizações e não indivíduos. Essa caracterização se refere ao fato de que as redes são compostas por organizações autônomas e, assim, são essencialmente empreendimentos cooperativos (Albers, 2005, 2010; Provan e Kenis, 2007; Roth e colaboradores, 2010; Wegner, 2011).

Desde que as redes não são entidades legais, o imperativo legal da governança não é o mesmo presente nas organizações individuais. Embora a governança em redes não seja uma questão legal, como na governança corporativa, Provan e Kenis (2007) apontam que ela é crítica para o desempenho das redes interorganizacionais. Ao contrário das organizações, as redes necessitam ser governadas sem os benefícios da hierarquia ou da propriedade. Portanto, o modelo de governança adotado pela rede é resultado de um processo de barganha entre os atores ou, de forma mais precisa, entre os decisores das organizações, levando em conta a opção de participar ou não dos relacionamentos a partir das considerações sobre os benefícios 
que tal participação pode trazer para os objetivos individuais. Nesse contexto, as organizações concordam em dispor de certa liberdade e submetem certos aspectos de sua atividade ao regime proposto pela governança da rede, o qual contém especificações relacionadas com o comportamento individual dos seus membros (Whetten e Leung, 1979).

Os termos que envolvem a governança da rede vinculam a organização e não os indivíduos que dela fazem parte. Isso significa que a organização precisa assegurar que, dentro dos seus domínios, os termos da governança da rede sejam cumpridos, tarefa realizada pelos seus gestores. A governança da rede, portanto, busca em última instância influenciar os gestores das organizações, enquanto autoridades de decisão dentro das organizações, a se comportar de forma que sustentem os propósitos coletivos (Doz e Hamel, 1998). A esse respeito, Inkpen (2000) observa que a rede interorganizacional não é um ator coletivo e a governança da rede é baseada em indivíduos que originalmente aderem e são partes da governança estabelecida.

Nessa concepção, a governança da rede resulta em um modelo supraorganizacional destinado a reunir os termos e condições específicos de um acordo. As organizações agem por meio dos seus membros e as diretrizes do arranjo interorganizacional precisam ser traduzidas para o contexto intraorganizacional. Esse processo de tradução para o nível organizacional não é domínio da governança da rede. O domínio da governança da rede, no caso deste estudo, foca exclusivamente as relações interorganizacionais as quais, entretanto, necessitam considerar as características das organizações que integram a rede. Nessa concepção, o sistema de governança se concentra nos mecanismos de coordenação, controle/monitoramento e incentivos. Ainda, considera os aspectos estruturais do sistema por meio da centralização e formalização (Albers, 2005). A governança dos relacionamentos entre duas ou mais organizações pode ser visualizada na figura 1.

Figura 1

Sistema de governança de segunda ordem

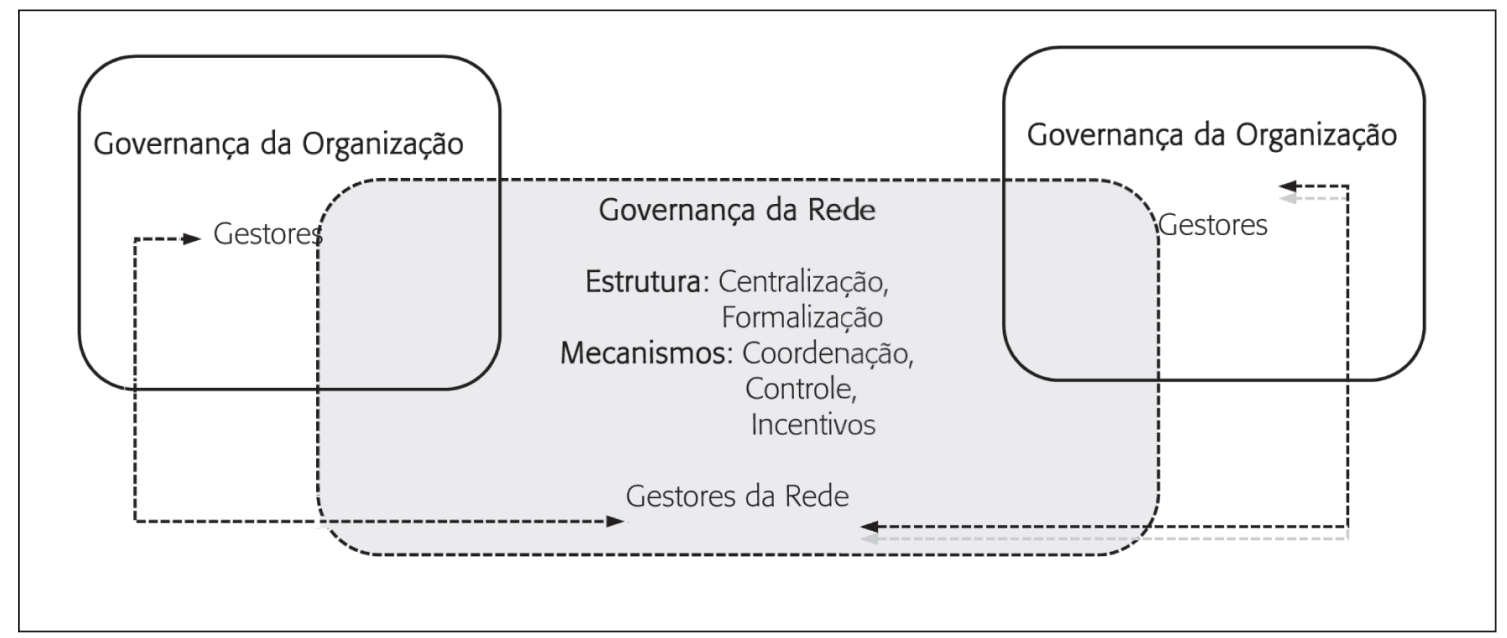

Fonte: Adaptada de Albers (2005), Roth e colaboradores (2010) e Wegner (2011). 
No entanto, as organizações que compõem os relacionamentos são ao mesmo tempo parte e objeto do sistema de governança estabelecido. Internamente, cada organização tende a ser afetada como resultado do desdobramento dos efeitos da governança da rede sobre a governança no nível organizacional (Child e Faulkner, 1998). Vista dessa forma, a governança da rede representa a introdução de um domínio adicional de governança que atua sobre as organizações que compõem a rede. Para Albers (2005), devido ao seu status complementar, a governança da rede representa um sistema de governança de segunda ordem. Tal status implica que o sistema de governança que opera nas organizações que integram a rede não é substituído, mas um novo nível de governança é adicionado. Entretanto, coloca algumas questões que devem ser consideradas em relação ao seu domínio e escopo. Assim, o sistema de governança da rede representa um tipo de supragovernança, uma vez que se estende ao longo das organizações que já possuem seu próprio sistema de governança e, de fato, os aspectos internos de cada organização, principalmente em relação às suas atividades produtivas, permanecem no domínio individual e, assim, são governados e organizados dentro das fronteiras organizacionais.

Além dos aspectos conceituais, pelos menos outras duas especificidades são relatadas na literatura como fatores de distinção da governança de redes e organizações, os quais, no entanto, podem ser em última instância relacionados com o fato de as redes não representarem um ator coletivo: i) natureza transitória e reversibilidade dos relacionamentos; e ii) a noção de que o mecanismo básico de tomada de decisão é formado pela barganha entre os atores. A natureza transitória e o caráter reversível dos relacionamentos dizem respeito à possibilidade que as organizações têm em interromper sua participação, mesmo que isso resulte em penalizações previstas nos termos acordados. Além disso, os termos acordados podem ser revistos pelos parceiros, uma vez que estes são parte e objeto da governança (Garrete e Dussauge, 2000). Outra especificidade diz respeito à tomada de decisão das redes e à sua tendência em se basear em um processo de barganha em que as principais decisões que afetam o grupo resultam de um consenso entre os parceiros (Parkhe, 1993). Isso também pode ser aplicado ao modelo de governança adotado pelo grupo como resultado de um processo de negociação entre os atores. As organizações, ou seja, os gestores que as representam, concordariam em participar do grupo e contribuir para o empreendimento desde que percebessem que seus respectivos interesses fossem respeitados na definição do modelo de governança. Uma vez que tal modelo é definido, podem-se codificar regras e regulamentos e, consequentemente, decisões futuras não necessariamente dependeriam de consenso no grupo, dependeriam dos mecanismos de governança empregados (Albers, 2010).

\subsection{Contexto institucional e governança de redes}

A noção de contexto institucional apresentada anteriormente a partir de diversos níveis está relacionada com as diferentes possibilidades de resposta às pressões ambientais que as organi- 
zações podem desenvolver (Scott, 1995). O pressuposto é o de que as interpretações diferentes do ambiente podem ser resultado do nível do contexto ao qual a organização se referencia. Como consequência, diferentes ações podem ser adotadas. Uma analogia pode ser feita em relação a padrões e valores diversos que podem influenciar as ações organizacionais quando se consideram diferentes níveis do contexto. Nesse sentido, certas ações podem decorrer de padrões institucionalizados em determinado contexto ambiental, no caso, aquele que é mais levado em conta pela organização (Machado-da-Silva e Barbosa, 2002). Na mesma linha de raciocínio, diferentes esferas institucionais usualmente denotam diferentes sistemas de crenças e valores, significando que a diversidade organizacional não pode ser explicada apenas por meio da cognição dos seus gestores, mas também pela própria diversidade simbólica no ambiente organizacional (Crubellate e Machado-da-Silva, 1998; Machado-da-Silva e Barbosa, 2002; Scott, 1987).

A estrutura teórica que compõe a teoria institucional é particularmente importante para esta proposta de estudo. O modelo de desenvolvimento e consolidação proposto para os APLs é resultado de ações de atores públicos e privados responsáveis por induzir os processos de consolidação de tais arranjos em suas regiões, como forma de promover o desenvolvimento das empresas locais e, consequentemente, o desenvolvimento das regiões. Assim, tal modelo é proposto por um conjunto de atores que definem as características de governança no contexto dos APLs.

Na relação ambiente-organização se privilegia uma noção em que se reconhecem os pressupostos da realidade socialmente construída, de forma que se abre espaço para a vertente cognitiva da teoria institucional, por meio da noção de ambiente técnico e institucional, em que se enfatiza o papel exercido por elementos simbólicos e externos à organização, ou seja, os valores ambientais, influenciando as ações dos atores. Tais valores ambientais são captados e a eles são atribuídos significados pelos atores e, caso institucionalizados, tendem a ser difundidos por meio dos condutores que os transmitem (Scott, 2008).

Nesse ponto, o contexto institucional de referência atua como elemento integrador entre os valores ambientais e os significados a eles atribuídos mediados pela visão de mundo dos atores. Assim, tem-se o elo que relaciona os valores ambientais com os valores no nível dos atores organizacionais. Isso abre espaço para a existência de diferentes grupos de referência (grupos de compartilhamento) entre os atores que se relacionam aos APLs resultando na presença de subculturas, em que a noção de valores retrata a questão da legitimidade das ações no interior dos arranjos produtivos (Guarido Filho e Machado-da-Silva, 2001). Desses argumentos, o compartilhamento de valores no nível dos atores organizacionais dá sentido legítimo às ações no interior dos APLs, afetando a sua dinâmica de funcionamento (governança). A figura 2 ilustra a relação entre os temas abordados.

Neste estudo se reconhece a contribuição da teoria institucional para a análise da relação entre a organização e seu ambiente, em que pressões de caráter técnico e institucional a forçam à conformidade de estrutura e práticas. Aliadas a essa visão, as abordagens mais recentes sobre a ação organizacional enfatizam o papel da cognição dos atores organizacionais reconhecendo que as organizações são ambientes ordenados a partir de interpretações desses 
atores. Nesse sentido, tais interpretações são produzidas por meio de processos dominados pela seletividade, fazendo com que as informações apreendidas e selecionadas resultem em diferentes significados atribuídos às mesmas condições externas (Gonçalves, 2007; Guarido Filho e Machado-da-Silva, 2001; Machado-da-Silva e Barbosa, 2002; Machado-da-Silva e Fonseca, 1996, 1999).

Figura 2

\section{Relação entre os temas abordados}

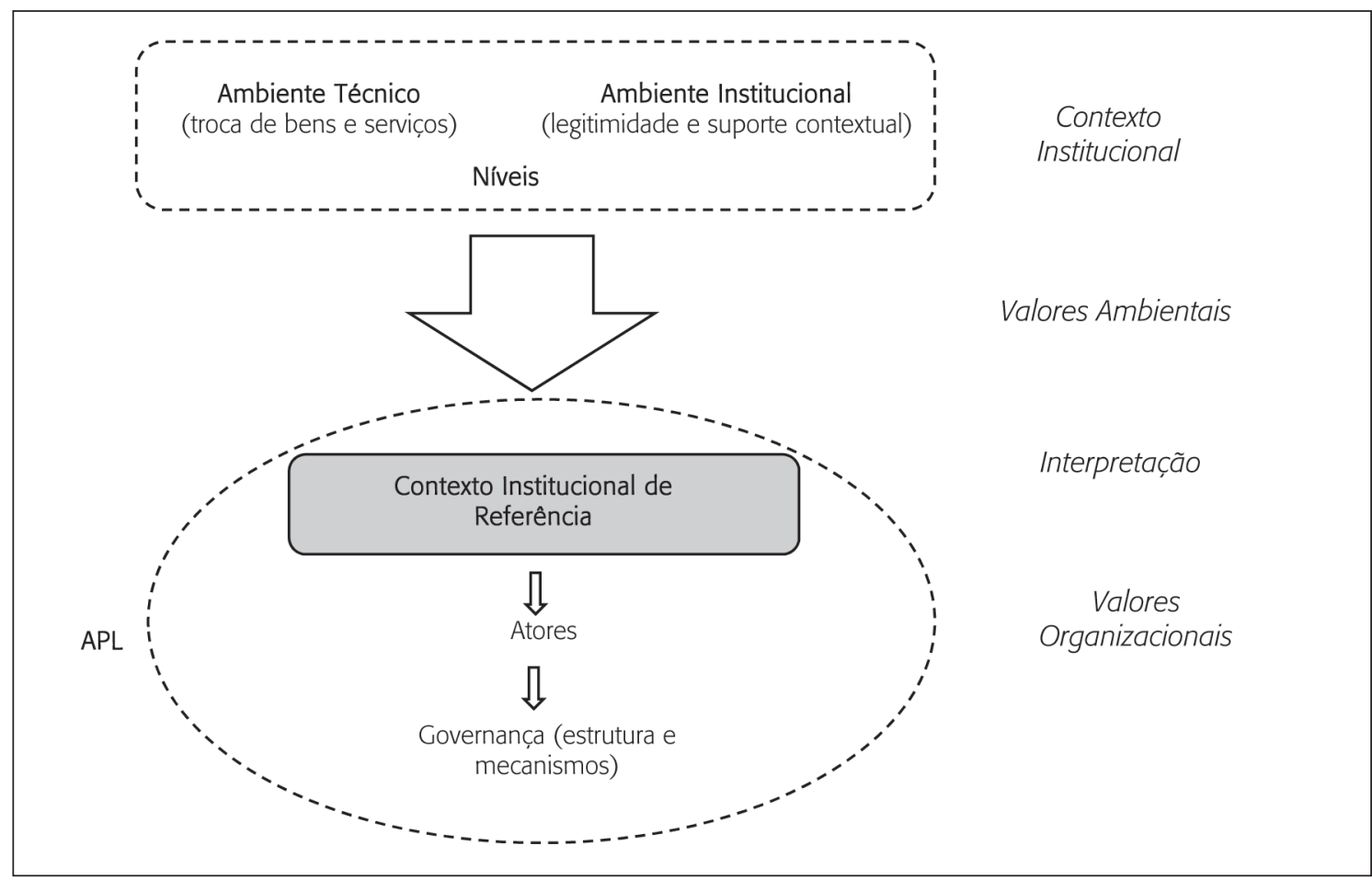

Fonte: Elaborada pelo autor a partir do referencial teórico e do modelo adotado por Guarido Filho e Machado-da-Silva (2001).

Essa noção suscita alguns questionamentos em relação ao contexto percebido pelos atores que compõem um APL. Nesse tipo de arranjo têm-se pelo menos dois grupos de atores: os atores que propõem a adoção do conceito de APL e os demais atores que são as empresas que integram os arranjos. Portanto, fundamentado no exposto anteriormente, supõe-se que não necessariamente esses dois grupos de atores compartilham um mesmo sistema de crenças e valores. A possibilidade de distintas interpretações do ambiente resulta também em diferentes contextos referenciados entre estes atores para suas ações (Machado-da-Silva e Barbosa, 2002; Scott, 1995). Pensando na possibilidade de que esses dois grupos compartilhem, em certo grau, um mesmo sistema de crenças e valores e, consequentemente, aproximem entre 
eles o contexto institucional adotado como referência, pode significar que os dois grupos atribuem significados semelhantes às mesmas pressões ambientais (Gonçalves, 2007; Guarido Filho e Machado-da-Silva, 2001; Machado-da-Silva e Barbosa, 2002; Machado-da-Silva e Fonseca, 1996, 1999). Portanto, as ações propostas pelo grupo responsável pela disseminação do conceito no estado do Paraná podem ser potencializadas no caso de aproximação da interpretação do ambiente entre esses dois grupos, de forma que afeta a configuração da governança (estrutura e mecanismos) presente nos APLs.

\section{Procedimentos metodológicos}

A população de APLs foco de políticas públicas no estado do Paraná é composta por 22 aglomerados identificados pelo Instituto Paranaense de Desenvolvimento Econômico e Social (Ipardes). A partir dos critérios da tipologia adotados pelo Ipardes (2006), procurouse selecionar casos que apresentassem maior grau de diferenças entre si, pois, assim, é possível reduzir explicações concorrentes aos fenômenos comuns encontrados em cada um dos casos. Além disso, casos diferentes em maior grau permitem expor com maior clareza os achados divergentes e convergentes entre os casos. Dessa forma, procurou-se selecionar APLs pertencentes a diferentes categorias definidas pelo Ipardes (2006); pertencentes a diferentes setores; diferentes regiões; com diferentes participações na economia local; e, ainda, diferentes em termos de características estruturais (número de empresas do arranjo). Além disso, a seleção dos APLs numa dada região levou em conta a situação atual do arranjo no momento da escolha, ou seja, foram escolhidos aqueles consolidados ou em processo de consolidação. Assim, os três APLs selecionados intencionalmente para serem pesquisados foram: i) Móveis de Arapongas; ii) Malhas de Imbituva; e iii) Software de Londrina.

A coleta de dados para este estudo se pauta no uso de múltiplas fontes de evidência (entrevistas, observações, documentos e questionários estruturados) por considerar o desenvolvimento de linhas convergentes de investigação, baseadas nos fundamentos da triangulação de fontes de dados. Como consequência, o uso de várias fontes de evidências e a triangulação de dados, além de atender aos critérios de validade, permitem ao pesquisador abordar os casos de uma forma mais ampla e completa mantendo o rigor metodológico exigido na produção do conhecimento científico (Godoy, 1995b; Yin, 2001).

As categorias definidas para estudo são representadas, por um lado, pelo contexto institucional de referência, o qual representa, por meio dos valores identificados, o nível de visualização dos ambientes técnico e institucional sob o ponto de vista do ator, podendo ser local/ regional, nacional e internacional, e serve como referencial para suas ações. Por outro lado, tem-se uma segunda categoria de análise representada pela governança da rede subdividida em duas dimensões: estrutura (centralização e formalização); e mecanismos (coordenação, controle e incentivos). 
A elaboração do roteiro de entrevista utilizado como principal instrumento de coleta qualitativa pautou-se essencialmente no quadro teórico utilizado, e sua validação buscou apoio na apreciação de pesquisadores com conhecimento nos temas abordados na pesquisa. Assim, foram consultados professores e doutorandos do programa de pós-graduação em administração da Universidade Federal do Paraná (UFPR), bem como pesquisadores pertencentes ao quadro de outras três instituições, os quais fizeram apontamentos e sugestões sobre os temas e questões que compuseram o roteiro de entrevista. Após a validação do instrumento, ao final da fase qualitativa, totalizaram-se 15 entrevistas realizadas, sendo: seis em Arapongas; cinco em Imbituva; e quatro em Londrina.

Já o questionário estruturado (composto de três blocos de questões), além de ter uma primeira versão resultante do quadro teórico e dos dados qualitativos, passou por um processo de validação apoiado na interação com especialistas e atores do campo de pesquisa.

Após a elaboração inicial do questionário estruturado, este foi submetido à avaliação de especialistas nos conceitos utilizados, sendo esses professores pesquisadores e doutorandos da UFPR, da Pontifícia Universidade Católica do Paraná (PUC-PR) e da Universidade Estadual do Centro-Oeste (Unicentro). Com os ajustes propostos por tais especialistas, o instrumento foi submetido à avaliação de dois professores com conhecimento estatístico (um da UFPR e outro da Unicentro) para avaliar a adequação das escalas para os futuros testes estatísticos. Depois de novos ajustes, foram consultados cinco empresários atuantes nos APLs pesquisados como forma de pré-teste e verificação da clareza dos termos e enunciados propostos no instrumento no sentido de identificar possíveis dificuldades por parte dos respondentes. Após os procedimentos de validação, a amostra final foi composta por 94 casos, sendo: 31 em Arapongas, 29 em Imbituva e 34 em Londrina.

A análise de dados compreendeu quatro fases: análise das entrevistas e documentos; análise dos questionários estruturados; verificação de padrões convergentes entre as evidências coletadas por meio da triangulação dos dados qualitativos e quantitativos obtidos; e validação das análises com especialistas e atores dos APLs.

Com relação às entrevistas, elas foram gravadas, transcritas e submetidas com os outros documentos à técnica de análise temática de conteúdo (Flick, 2009; Laville e Dionne, 1999). Considerando que a pesquisa qualitativa "parte de questões ou focos de interesses amplos, que vão se definindo à medida que o estudo se desenvolve" (Godoy, 1995a:58), a construção das categorias de análise utilizou um modelo do tipo misto (Laville e Dionne, 1999).

Com relação à segunda fase da análise de dados, foram utilizadas técnicas estatísticas de análise para identificar a relação entre as variáveis e testar hipóteses tais como: distribuição de frequência, medidas de tendência central, tabulações cruzadas, análise de cluster, comparação de médias e testes de correlação.

$\mathrm{Na}$ terceira fase da análise de dados, as entrevistas semiestruturadas, os documentos e os questionários foram foco da técnica de triangulação, de forma que se buscaram encontrar padrões convergentes entre os resultados para se alcançar maiores consistência e confiabilidade com relação aos resultados da análise (Flick, 2009; Laville e Dionne, 1999). 


\section{Análise conjunta dos casos: especificidades e traços comuns}

O esforço em concretizar o potencial de desenvolvimento de determinadas regiões produtivas paranaenses teve seu auge por volta da metade da década de 2000, período em que as regiões de Arapongas, Imbituva e Londrina foram classificadas como APLs a partir de metodologia específica baseada em um conceito então disseminado em nível nacional.

A partir da análise do conceito de APL propagado no estado, do perfil das entidades envolvidas e do foco das ações desenvolvidas, é possível observar que o contexto institucional de referência associado ao modelo diz respeito ao nível internacional devido aos valores identificados, os quais são mais consistentes com esse nível. O conjunto de valores representa que os atores envolvidos na disseminação no conceito de APL no estado do Paraná buscam apoiar as empresas no sentido de desenvolver ou expandir sua participação no mercado internacional praticando intensa monitoração da concorrência estrangeira. Desse modo, o desenvolvimento dos arranjos produtivos a partir desse conceito privilegia a modernização das empresas, de modo que permita o melhor atendimento das demandas de mercado, assim como procura acompanhar as tendências de consumo mundial e satisfazer os requisitos de qualidade, diversificação de linhas de produtos e sustentabilidade socioambiental; além disso, é marcante a noção de cooperação presente no conceito de forma a permitir a aprendizagem, inovação e desenvolvimento global do arranjo. O papel do estado nesse nível se dá em facilitar o acesso aos mercados internacionais e desenvolver políticas específicas de apoio às empresas inseridas nos arranjos produtivos. Essa síntese de valores extraídos do modelo paranaense de APL e das respectivas entidades envolvidas em sua disseminação é coerente com aqueles encontrados em estudos anteriores, como os de Guarido Filho (2000), Guarido Filho e Machado-da-Silva (2001) e Machado-da-Silva e Barbosa (2002).

$\mathrm{Na}$ análise individual de cada APL, a triangulação entre os dados qualitativos e quantitativos revela que os valores referenciados pelas empresas de Arapongas e Imbituva são mais consistentes com o nível internacional, enquanto Londrina parece ser mais consistente com o nível nacional do contexto de referência. Isso não significa dizer que os casos podem ser classificados como puramente internacional ou nacional, mas que apresentam um conjunto de valores mais marcantes em determinado nível do contexto, ou seja, aquele que é mais levado em consideração pelas organizações que compõem os respectivos arranjos, conforme destacado pela literatura (e.g., Guarido Filho, 2001; Machado-da-Silva e Barbosa, 2002; Machadoda-Silva e Fonseca, 1996, 1999).

No caso do arranjo de Arapongas, nota-se que o setor de móveis é afetado por padrões de consumo internacionais, principalmente relacionados com o design de móveis, de forma que os padrões de desenvolvimento de produtos são rapidamente disseminados no contexto nacional. Isso pressiona as organizações do setor a adotar não somente os padrões de design, mas também de produção por meio da adoção de tecnologias sustentáveis e desenvolvimento de inovações dentro do arranjo. E isso é mais presente ainda naquelas empresas que atuam ou têm pretensões de atuação no mercado exterior. Assim, mesmo que o arranjo seja composto essencialmente por empresas que atuam no mercado nacional, o padrão de consumo, de 
produção e, consequentemente, o padrão competitivo parecem ser mais consistentes com o nível internacional. Além disso, trabalhos como os de Guarido Filho (2000) e Guarido Filho e Machado-da-Silva (2001) atestam as tendências associadas ao nível internacional presentes na indústria nacional compondo os contornos que definem o ambiente da maior parte das indústrias deste país.

No entanto, mesmo que o contexto internacional predomine no arranjo de Arapongas, aspectos delimitados no nível nacional e local/regional também estão presentes, como as fracas relações de cooperação entre fornecedores e concorrentes, concentração nos ganhos de escala como estratégia de competição, reatividade em face de situações ambientais, noção de qualidade como diferencial competitivo e preocupação com as políticas nacionais de apoio e incentivo.

Para o caso de Imbituva, os dados qualitativos e quantitativos convergem no sentido de que o contexto institucional de referência predominante é o internacional. Mesmo que a atuação das empresas do arranjo em sua totalidade não extrapole os limites do mercado nacional, aquele arranjo parece ser sensível aos padrões internacionais de consumo e produção em razão da presença crescente dos produtos importados no mercado nacional. Isso pressiona as empresas do setor de malharias como um todo a adotar padrões competitivos globais para seus produtos e processos produtivos. Nesse caso em específico, a principal pressão de origem internacional está relacionada com os preços praticados pelos concorrentes nesse nível do contexto, fazendo com que o setor como um todo se volte para diferenciais competitivos que não o custo como alternativa à competição, investindo em ações competitivas baseadas na qualidade e diferenciação a partir de nichos específicos do mercado, aspectos também identificados por Machado-da-Silva e Barbosa (2002). No caso de Imbituva, também são encontrados valores do nível local/regional e nacional, com certo destaque a aspectos como fracas relações de cooperação com os fornecedores e concorrentes, reatividade perante situações ambientais, e preocupação com as políticas nacionais de apoio e incentivo.

Já o arranjo de Londrina parece ser mais afetado por valores presentes no nível nacional do contexto institucional de referência. Isso foi identificado por meio da interpretação dos dados qualitativos e fortemente corroborado pelos resultados quantitativos desta pesquisa. Portanto, mesmo que a presença de padrões internacionais de consumo e o desenvolvimento de produtos e serviços afetem as empresas daquele arranjo, outros aspectos como a baixa sensibilidade às flutuações externas da economia, a tendência ao pouco impacto da ação de concorrentes externos no país e o relacionamento de médio e longo prazo com os clientes, o qual exige proximidade geográfica e personalização dos serviços; convergem para um nível nacional como contexto predominante no conjunto de valores dos atores daquele arranjo.

A principal explicação para as diferenças apontadas em termos de nível de visualização do contexto institucional e os respectivos valores entre os APLs reside na ideia de que tanto o ambiente técnico quanto o institucional podem se revelar estrutural e simbolicamente diferentes de acordo com o setor, podendo, ainda, apresentar conotação diversa ao se levarem em consideração os diferentes níveis do contexto institucional. Tais diferenças são resultado da concreta possibilidade de diferentes valores ou de diferentes significados atribuídos aos mes- 
mos valores pelos atores sociais em diferentes níveis do contexto, corroborando os achados de estudos anteriores (e.g., Machado-da-Silva e Barbosa, 2002; Machado-da-Silva e Fonseca, 1996, 1999; Scott, 1992).

A análise da governança presente nos arranjos aqui estudados também revela diferenças marcantes entre eles. Do ponto de vista da estrutura, foram consideradas duas dimensões: centralização e formalização. No que diz respeito à centralização, os dados demonstram que os três arranjos adotam um modelo compartilhado de decisão caracterizado pela intermediação das decisões por meio de uma entidade denominada pela literatura como a "organização administrativa da rede" (Provan e Kenis, 2007; Roth et al., 2010; Wegner, 2011). Nesse modelo, a governança é concentrada em um ou poucos atores com autoridade para exercer o papel junto aos demais membros do grupo. Como apresentado pela literatura, as diferenças nos APLs estudados se encontram na forma e no grau em que a intermediação (compartilhamento) ocorre, de maneira que os dados quantitativos demonstraram diferenças mais marcantes entre o arranjo de Arapongas e os demais. Assim, cada um dos APLs estudados se enquadra entre um continuum entre uma situação compartilhada e centralizada de decisão (Wegner, 2011).

No arranjo de Arapongas são identificadas duas entidades que poderiam se enquadrar como responsáveis pela intermediação das decisões. A entidade criada como a governança do APL, apesar de ainda ter reuniões e contar com a participação de alguns empresários, parece não ter influência sobre o funcionamento do arranjo e das ações coletivas que são encaminhadas, pois tem pouca visibilidade por parte das empresas, chegando ao ponto de alguns empresários visitados não terem o conhecimento de sua existência. Os dados qualitativos demonstram que o papel de intermediador de decisões é desempenhado pelo sindicato que representa a indústria de móveis da região. Outra característica marcante reside no grau com que as decisões são compartilhadas com os demais membros do arranjo e, no caso, com os associados do sindicato. Nota-se que, mesmo adotando um modelo compartilhado de decisão, o grau de compartilhamento é reduzido a poucas pessoas que compõem a direção do sindicato, de forma que poucas são as oportunidades em que os demais associados participam das decisões, conforme convergem os dados qualitativos e quantitativos desta pesquisa.

Situação parecida ocorre no arranjo de Imbituva, onde a governança formada no APL não representa a principal entidade em termos de intermediação das decisões. Nesse caso, mesmo os empresários tendo o conhecimento de que existe uma entidade com esse fim, esse papel é desempenhado pela associação das malharias. Nota-se que as decisões de caráter rotineiro ou de pouco impacto sobre o APL são tomadas em nível de diretoria ou de comitê gestor de cada área e que decisões de maior importância são compartilhadas com os demais membros da associação, demonstrando maior compartilhamento de decisões comparativamente ao arranjo de Arapongas.

Por sua vez, no arranjo de Londrina, a principal entidade responsável pela intermediação das decisões é a própria governança formada com a criação do APL. Nesse caso, nota-se um alto grau de compartilhamento de decisões. Mesmo contando com um corpo de membros responsáveis pela gestão, as constantes interações entre os empresários e entidades permitem 
uma frequência maior de encontros e decisões compartilhadas, conforme previsto por Albers (2005, 2010).

Em relação à formalização da estrutura de governança, ela diz respeito ao grau no qual os termos para os relacionamentos acordados, regras e regulamentações para as diferentes contingências são predefinidos, descritos e fixados, além das respostas adequadas a tais contingências (Grandori e Soda, 1995). Para essa categoria, os resultados encontrados são semelhantes aos encontrados em relação à centralização, de modo que o arranjo de Arapongas é diferente dos demais, em que menor grau de formalização foi encontrado no APL de Arapongas, e os arranjos de Imbituva e Londrina apresentam um grau de formalização maior e semelhante entre si. Mesmo se identificando diferenças em termos de formalização nos APLs, isso não significa que os arranjos de Imbituva e Londrina adotem um modelo em que todas as ações são previstas e detalhadas em documentos. O que se percebe do conjunto dos dados é que esses dois APLs adotam maior grau de organização de suas ações, o que se reflete na percepção sobre o grau de formalização enquanto base contratual dos relacionamentos entre os atores (Albers, 2010; Grandori e Soda, 1995).

Os mecanismos de governança representam a dimensão processual do sistema de governança da rede e sua função básica é promover a coordenação em um sentido que as atividades dos diferentes atores forneçam o suporte para os interesses coletivos, bem como promovam os incentivos para a participação dos atores de acordo com tais interesses (Oxley, 1997). Desse modo, a avaliação dos mecanismos de governança dos três arranjos objeto dessa pesquisa considerou aspectos relacionados com a coordenação, controle e incentivos. Nesse sentido, para essas três dimensões os resultados foram semelhantes, apresentando o APL de Arapongas como diferente dos demais.

O grau de interação presente nos arranjos parece afetar os aspectos de coordenação e controle nos arranjos estudados. Isso se verifica ao se considerarem as oportunidades de interação entre aqueles atores por meio do conteúdo e da frequência em que são realizadas reuniões. No caso de Arapongas se nota pouca frequência de reuniões entre os atores e, quando ocorre, a participação é limitada. Frequência maior é encontrada no arranjo de Imbituva, onde as reuniões são periódicas e se intensificam em época prévia à realização da feira de malhas. Por sua vez, o arranjo de Londrina se destaca por adotar um modelo de coordenação em que os membros do arranjo se reúnem semanalmente para discutir ações de trocar informações e conhecimentos. A frequência com que ocorrem os encontros também parece afetar os mecanismos de controle, pois oportuniza momentos em que se avaliam as ações coletivas e se definem as possíveis correções necessárias, caracterizando uma forma de controle baseada em resultados (Albers, 2005; Wegner, 2011). Além disso, esses momentos também permitem que se discutam coletivamente ações para combater práticas oportunistas dentro do arranjo e até mesmo entre os membros da governança. Assim, os dados evidenciam que não somente a frequência em que os membros do arranjo têm oportunidade de interagir, mas também o conteúdo das interações afetam o arranjo em termos de coordenação e controle. Isso parece ser coerente com o que autores como Albers (2005) e Grandori e Soda (1995) denominaram de ajuste mútuo em sua forma mais estruturada, pois envolvem fóruns institucionalizados ou 
comitês, os quais dão uma base regular aos processos de comunicação. A partir desses fóruns e comitês, percepções, necessidades e requisitos em relação ao desempenho das atividades de cooperação são discutidos entre os parceiros.

Contudo, merece destaque que os resultados alcançados pela disseminação do conceito de APL parecem ser mais fruto da iniciativa dos atores locais, principalmente empresários do setor, e menos da articulação de entidades externas de apoio. Tal evidência em relação às interações entre os atores sociais remete à condição prototípica da instituição no sentido de estar frente a frente um com o outro. De acordo com Berger e Luckmann (2009), toda a dinâmica relacionada com a formação das realidades sociais está intimamente ligada à situação face a face em que as pessoas se relacionam umas com as outras. Nesse encontro, as subjetividades das pessoas se confrontam continuamente. Dessa confrontação, tais subjetividades são modificadas/transformadas, tornando as realidades sociais objetiváveis, e isso é construído na situação cotidiana em que as pessoas, a todo instante, interagem. A partir do momento que as diversas realidades se tornam partilháveis, elas ganham existência própria, ou seja, elas se tornaram objetivas. Então, por trás do funcionamento de toda a dinâmica da cooperação interorganizacional estão diversos fatores, mas aqueles que ganham relevância são o encontro face a face e o processo de objetivação da realidade (Berger e Luckman, 2009).

Os resultados da análise do conceito de APL e das características e ações das entidades responsáveis pela sua disseminação no estado do Paraná permitiram identificar um conjunto de valores de caráter técnico e institucional predominantemente relacionados com traços internacionais no contexto de referência. No nível dos APLs, os dados qualitativos e quantitativos apresentaram convergência permitindo que se determinasse que o nível internacional é o que mais afeta os APLs de Arapongas e Imbituva e que, no caso de Londrina, o contexto nacional seja considerado como predominante.

Analisando mais detidamente os valores que compõem o contexto institucional de referência de cada grupo de atores, conclui-se que eles são estruturalmente diferentes entre si, ou seja, mesmo que grupos de atores compartilhem um mesmo nível do contexto institucional, os valores que integram cada um deles se mostram diferentes. Dentre os valores que integram contexto associado ao conceito de APL, os resultados demonstram que o desenvolvimento de relacionamentos de cooperação no arranjo é um dos mais marcantes e, assim como encontrado na literatura sobre redes e aglomerações produtivas, parece ser esse o principal aspecto que, compartilhado entre os mais diferentes atores, afeta positivamente a dinâmica de funcionamento de um arranjo (Amato Neto, 2000; Child e Faulkner, 1998; Ring e Van de Ven, 1992).

Dito isso, no caso de Arapongas, as evidências parecem convergir no sentido de que as empresas que integram aquele arranjo não compartilham as interações colaborativas como um valor importante para as suas ações, de forma que, como explicitado nos capítulos específicos, as ações de cooperação são limitadas a poucos atores e os demais exemplos se mostram como casos isolados, não representando uma prática disseminada naquele aglomerado. No caso de Imbituva, a cooperação, mesmo que ainda fraca, parece ser mais presente em comparação com Arapongas. No entanto, o conteúdo da colaboração encontrada em Imbituva, e 
que ocorre de forma constante, tem um sentido utilitário de maneira a permitir a organização e participação na feira de malhas. Situação diferente desses dois arranjos é a encontrada em Londrina, em que a cooperação possui uma conotação diferente, de forma que é mais presente e parece representar um sentido próximo daquele encontrado no conceito de APL em que a cooperação é uma forma de desenvolver relacionamentos duradouros e constantes em prol de benefícios coletivos.

Tais diferenças relatadas em relação ao sentido dado à cooperação em cada um dos arranjos parecem ser resultado do papel da cognição daqueles atores organizacionais no sentido de que as organizações são ambientes ordenados a partir de interpretações desses atores. Nesse sentido, tais interpretações são produzidas por meio de processos dominados pela seletividade, fazendo com que as informações apreendidas e selecionadas resultem em diferentes significados atribuídos às mesmas condições externas (Gonçalves, 2007; Guarido Filho e Machado-da-Silva, 2001; Machado-da-Silva e Barbosa, 2002; Machado-da-silva e Fonseca, 1996, 1999).

Portanto, fundamentado no exposto, esses dois grupos de atores (entidades e empresas) não compartilham um mesmo sistema de crenças e valores dados às distintas interpretações do ambiente que resultam também em contextos de referência estruturalmente diferentes para suas ações. As evidências encontradas neste estudo permitem considerar que o sistema de crenças e valores de diferentes grupos de atores, em que a cooperação aparece como um valor compartilhado, pode significar que os dois grupos atribuem significados semelhantes às mesmas pressões ambientais (Gonçalves, 2007; Guarido Filho e Machado-da-Silva, 2001; Machado-da-Silva e Barbosa, 2002; Machado-da-Silva e Fonseca, 1996, 1999).

Do ponto de vista das características da governança presentes em cada APL, Arapongas se mostrou como aquele em que as dimensões analisadas são menos presentes, de modo que se caracteriza pelo baixo compartilhamento de decisões, pouca formalização e poucos mecanismos de coordenação, controle e incentivos. Diferentemente, nos arranjos de Imbituva e Londrina, nota-se uma maior presença dos elementos que compõem a governança, na forma de maior compartilhamento de decisões, formalização, e a presença de mecanismos de coordenação, controle e incentivos (Albers, 2005, 2010; Wegner, 2011). Chama a atenção que o principal mecanismo de coordenação utilizado por Imbituva e Londrina é representado pelas reuniões, o que ocorre em maior grau no caso de Londrina. Tais reuniões proporcionam oportunidades de interação entre as empresas e isso parece estar relacionado com a presença da cooperação como um valor relevante para promover maiores interações entre aqueles atores.

Diante disso, os dados parecem evidenciar que a cooperação, como aspecto valorizado no ambiente e traduzido em ações, é mais presente naqueles arranjos que também possuem sistemas de governança mais estruturados a partir dos elementos avaliados. É possível considerar que a maior aproximação da interpretação do ambiente entre esses dois grupos (os que propõem o modelo de APL e as empresas) em relação à cooperação afeta a configuração da governança presente nos APLs.

Como forma de ilustrar as principais diferenças e semelhanças apresentadas anteriormente entre os arranjos pesquisados, o quadro 1 sintetiza as características de cada APL a partir das categorias utilizadas neste estudo. 
Quadro 1

\section{Comparativo entre os APLs}

\begin{tabular}{|c|c|c|c|c|}
\hline \multicolumn{2}{|r|}{ Características } & Arapongas & Imbituva & Londrina \\
\hline \multicolumn{2}{|r|}{$\begin{array}{l}\text { Contexto } \\
\text { Institucional de } \\
\text { Referência }\end{array}$} & Internacional & Internacional & Nacional \\
\hline$\frac{\mathscr{0}}{\frac{0}{\pi}}$ & & 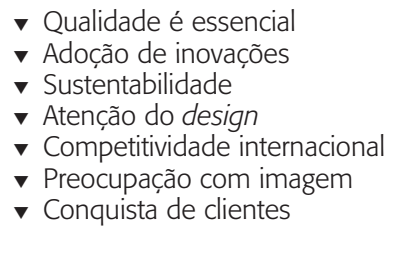 & 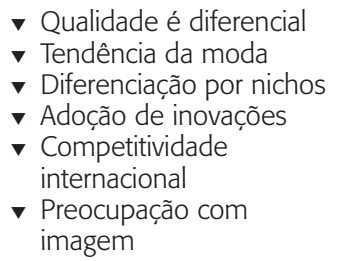 & 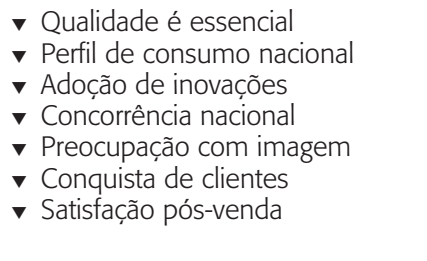 \\
\hline \multirow{5}{*}{ 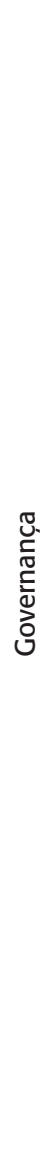 } & Centralização & $\begin{array}{l}\text { Voucos atores decidem } \\
\text { V Compartilhamento reduzido } \\
\text { Entidade de governança não } \\
\text { consolidada }\end{array}$ & $\begin{array}{l}\text { - Poucos atores decidem } \\
\text { com aval dos demais } \\
\text { vecisões importantes } \\
\text { são compartilhadas } \\
\text { v Entidade de governança } \\
\text { não consolidada }\end{array}$ & $\begin{array}{l}\text { Alto grau de compartilhamento } \\
\text { vaioria das decisões permite a } \\
\text { participação de todos } \\
\text { v Consolidação da entidade de } \\
\text { governança }\end{array}$ \\
\hline & Formalização & $\begin{array}{l}\text { v Estatuto do sindicato } \\
\text { จ Documentos definem apenas } \\
\text { funções a serem ocupadas } \\
\text { จ Planejamento documentado } \\
\text { e não atualizado }\end{array}$ & $\begin{array}{l}\text { Vstatuto da associação } \\
\text { v Termo de adesão à feira } \\
\text { v Planejamento } \\
\text { formalizado } \\
\text { v Poucos registros sobre } \\
\text { as reuniões e decisões } \\
\text { tomadas }\end{array}$ & $\begin{array}{l}\text { Regimento genérico e regimento } \\
\text { detalhado do Cintec (vinculado à } \\
\text { governança) } \\
\text { v Registros em ata das reuniões }\end{array}$ \\
\hline & Coordenação & $\begin{array}{l}\text { voucas reuniões e } \\
\text { oportunidades de interação } \\
\text { v Reuniões em função da feira } \\
\text { v Maior presença de entidades } \\
\text { do que empresários } \\
\text { v Comunicação deficiente entre } \\
\text { governança e empresários } \\
\text { v Poucos conhecem o conceito } \\
\text { de APL }\end{array}$ & $\begin{array}{l}\text { Reuniões a partir de } \\
\text { demandas (feira) } \\
\text { Vealizada pela associação } \\
\text { - Conhecimento sobre o } \\
\text { conceito de APL }\end{array}$ & 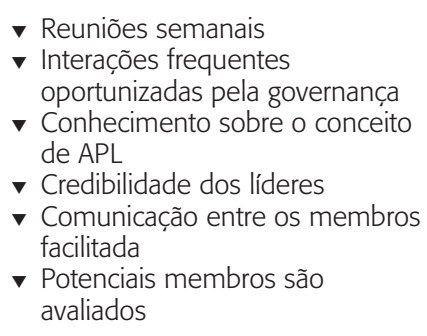 \\
\hline & Controle & $\begin{array}{l}\text { V Por resultados } \\
\text { v Sem instrumentos elaborados } \\
\text { v Avaliação das ações em } \\
\text { reuniões }\end{array}$ & $\begin{array}{l}\text { Vor resultados } \\
\text { v Sem instrumentos } \\
\text { elaborados } \\
\text { v Avaliação das ações em } \\
\text { reuniões }\end{array}$ & $\begin{array}{l}\text { Vonitoramento dos processos } \\
\text { v Por resultados } \\
\text { v Oportunismo afeta a reputação } \\
\text { v Ferramentas tecnológicas para } \\
\quad \text { avaliar as ações }\end{array}$ \\
\hline & Incentivos & $\begin{array}{l}\text { Vem ações específicas } \\
\text { - Sem benefícios para as } \\
\text { grandes empresas } \\
\text { v Ações não atingem as MPEs }\end{array}$ & $\begin{array}{l}\text { จ Sem ações específicas } \\
\text { v Participação na feira } \\
\text { v Sentido utilitário }\end{array}$ & $\begin{array}{l}\text { V Sem ações específicas } \\
\text { } \text { Sentido de pertencimento de } \\
\text { um empreendimento coletivo } \\
\text { v Credibilidade dos líderes }\end{array}$ \\
\hline
\end{tabular}

Fonte: Dados primários e secundários da pesquisa. 


\section{Considerações finais}

A perspectiva institucional adotada neste estudo, a partir de uma ênfase no local e, consequentemente, no ator, potencializou a contribuição deste estudo no sentido de que permitiu uma compreensão contextualizada das redes interorganizacionais, representadas, aqui, pelos APLs.

No contexto brasileiro, o reconhecimento das aglomerações produtivas como alternativa para o desenvolvimento é um fenômeno relativamente recente, de modo que teve intensa difusão no país, substituindo termos afins nas agendas de políticas públicas a partir de seu desenvolvimento no final dos anos de 1990. Desde então, esforços foram realizados para a promoção e compreensão do fenômeno, tendo ocorrido nesse período inicial um intenso processo de aprendizado e de internalização de conhecimentos.

No que diz respeito ao modelo de APL, a análise do conceito em si, dos atores envolvidos e suas ações demonstrou que o contexto institucional de referência a eles associado é composto predominantemente por valores relacionados com o nível internacional. Em uma análise mais apurada dos valores que constituem o contexto institucional referenciado por esses atores, nota-se que os elementos que o compõem são caracterizados essencialmente pela dimensão institucional, de forma que as pressões de caráter técnico são menos presentes no contexto de referência daqueles atores que propõem o modelo. Conforme mencionado por Scott e Meyer (1991), tal constatação é explicada pela natureza dos atores que compõem a rede APL e foram responsáveis pela disseminação de tal noção no estado. Basicamente, são entidades ligadas à esfera pública, de ensino e pesquisa ou representativas de classe, as quais são menos afetadas por pressões de caráter técnico.

A compreensão ou a explicação de alguma ação exige a consideração de condições objetivas, bem como a interpretação subjetiva do ator (Scott, 2008). Esse pressuposto básico do pilar cognitivo da teoria institucional permitiu demonstrar que o contexto institucional de referência dos distintos grupos de atores estudados é estruturalmente diferente no sentido de que os valores que compõem o contexto têm origens em diferentes dimensões (técnica ou institucional) do ambiente. Assim, a partir de uma análise mais apurada dos elementos presentes no contexto referenciado pelos atores, foi possível perceber que os valores relacionados com a cooperação têm presença destacada no conjunto dos elementos identificados no modelo de APL e aparecem em graus diferenciados entre os arranjos estudados.

A análise da relação entre os elementos da governança, por meio dos dados quantitativos e com o auxílio dos dados qualitativos, permitiu evidenciar que os arranjos mais ordenados em termos de governança, ou seja, que apresentam maior adoção dos elementos pesquisados (compartilhamento de decisões, formalização, controle, coordenação e incentivos), também apresentam maiores efeitos das ações do APL sobre as empresas pesquisadas. Isso claramente corrobora os estudos sobre governança de redes no sentido de que seu funcionamento e sua capacidade de produzir resultados são afetados pelo sistema de governança que opera na rede. De maneira mais específica, os dados parecem evidenciar 
que o compartilhamento de determinados valores entre os diferentes grupos de atores envolvidos com arranjos produtivos se relaciona positivamente com o maior grau de presença dos elementos de governança. Também se evidenciou um possível padrão nas relações encontradas no sentido de que o compartilhamento dos valores relacionados com a cooperação parece ser determinante para que a relação entre contexto institucional de referência e governança seja positiva.

Essa pode ser considerada uma das principais contribuições deste estudo, pois a forma com que os atores se organizam no contexto dos arranjos produtivos parece ser fruto das relações locais, independentemente do nível do contexto em que se referenciam, de maneira que, como apresentam Berger e Luckmann (2009), a condição prototípica da instituição se dá no sentido de estar frente a frente com o outro, e toda a dinâmica relacionada com a formação das realidades sociais está intimamente ligada à situação de interação face a face, de modo que diversas realidades se tornam partilháveis, ganham existência própria e se tornam objetivas. Portanto, a consolidação do modelo de APLs no estado do Paraná parece condicionada à promoção de situações em que as principais interações se deem no nível local e protagonizadas pelos atores locais.

\section{Referências}

ALBERS, Sasha. Configurations of alliance governance systems. Schumalenbach Business Review, n. 62, p. 204-233, 2010.

ALBERS, Sasha. The design of Alliance Governance Systems. Köln: KölnerWissenschaftsverlag, 2005.

AMATO NETO, João. Redes de cooperação produtiva e clusters regionais: oportunidades para as pequenas e médias empresas. São Paulo: Atlas, 2000.

BERGER, Peter L.; LUCKMANN, Thomas. A construção social da realidade. 30. ed. Petrópolis: Vozes, 2009.

CHILD, John; FAULKNER, David. Strategies of co-operation: managing alliances, networks, and joint ventures. Nova York: Oxford University Press, 1998.

CRUBELLATE, João M.; MACHADO-DA-SILVA, Clóvis L. Valores/crenças e interesses como mediadores de adaptação organizacional à mudança ambiental: estudo comparativo de casos. In: ENCONTRO NACIONAL DA ASSOCIAÇÃO DOS PROGRAMAS DE PÓS-GRADUAÇÃO EM ADMINISTRAÇÃO, 22, 1998, Foz do Iguaçu. Anais... Foz do Iguaçu: ANPAD, 1998. 1 CD-ROM.

DIMAGGIO, Paul J.; POWELL, Walter W. The iron cage revisited: institutional isomorphism and collective rationality in organizational fields. American Sociological Review, v. 48, n. 2, p. 147-160, 1983.

DOZ, Yves L.; HAMEL, Gary. Alliance advantage: the art of creating value through partnering. Boston: Harvard Business School Press, 1998. 
FLICK, Uwe. Uma introdução à pesquisa qualitativa. Porto Alegre: Bookman, 2009.

GARRETE, Bernard; DUSSAUGE, Pierre. Alliance versus acquisitions: choosing the right options. European Management Journal, v. 18, n. 1, p. 63-69, 2000.

GODOY, Arilda S. Introdução à pesquisa qualitativa e suas possibilidades. Revista de Administração de Empresas, v. 35, n. 2, p. 57-63, 1995a.

GODOY, Arilda S. Pesquisa qualitativa: tipos fundamentais. Revista de Administração de Empresas, v. 35 , n. 3, p. 20-29, 1995 b.

GONÇALVES, Sandro A. Mudança estratégica, esquemas interpretativos e contexto institucional: um estudo de caso longitudinal. Revista Eletrônica de Ciência Administrativa, v. 6, n. 2, 2007. Disponível em: <http://revistas.facecla.com.br/index.php/recadm/article/view/122>. Acesso em: 20 jul. 2013.

GRANDORI, Anna; SODA, Giuseppe. Inter-firm networks: antecedents, mechanisms and forms. Organizations Studies, v. 16, n. 2, p. 183-232, 1995.

GREENWOOD, Royston; HINNINGS, Christopher R. Organizational design types, tracks and the dynamics of strategic change. Organization Studies, v. 9, n. 3, p. 293-316, 1988.

GUARIDO FILHO, Edson R. Influências contextuais e culturais sobre a aprendizagem organizacional: um estudo no setor alimentício do Paraná. Dissertação (mestrado em administração) — Universidade Federal do Paraná, Curitiba, 2000.

GUARIDO FILHO, Edson R.; MACHADO-DA-SILVA, Clóvis L. A influência dos valores ambientais e organizacionais sobre a aprendizagem organizacional na indústria alimentícia paranaense. Revista de Administração Contemporânea, v. 5, n. 2, p. 33-63, 2001.

IPARDES. Instituto Paranaense de Desenvolvimento Econômico e Social. Arranjos produtivos locais do estado do Paraná: identificação, caracterização e construção de tipologia. Curitiba: Secretaria de Estado do Planejamento e Coordenação Geral; Ipardes, 2006.

INKPEN, Andrew C. A note on the dynamics of learning alliances: competition, cooperation, and relative scope. Strategic Management Journal, v. 21, n. 7, p. 775-779, 2000.

LAVILLE, Christian; DIONNE, Jean. A construção do saber: manual de metodologia da pesquisa em ciências humanas. Belo Horizonte: UFMG, 1999.

MACHADO-DA-SILVA, Clóvis L.; BARBOSA, Suzana L. Estratégia, fatores de competitividade e contexto de referência das organizações: uma análise arquetípica. Revista de Administração Contemporânea, v. 6, n. 3, p. 7-32, 2002.

MACHADO-DA-SILVA, Clóvis L.; FERNANDES, Bruno H. R. Mudança ambiental e reorientação estratégica: estudo de caso em instituição bancária. Revista de Administração de Empresas, v. 38, n. 4, p. 46-56, 1998. 
MACHADO-DA-SILVA, Clóvis L.; FONSECA, Valéria S. Competitividade organizacional: conciliando padrões concorrenciais e padrões institucionais. In: VIEIRA, Marcelo M. F.; OLIVEIRA, Lúcia M. B. (Org.). Administração contemporânea: perspectivas estratégicas. São Paulo: Atlas, 1999. p. 27-40.

MACHADO-DA-SILVA, Clóvis L.; FONSECA, Valéria S. Competitividade organizacional: uma tentativa de reconstrução analítica. Organizações e Sociedade, v. 4, n. 7, p. 97-114, 1996.

MEYER, John W.; ROWAN, Brian. Institutional organizations: formal structure as myth and ceremony. American Journal of Sociology, v. 83, n. 2, p. 340-363, 1977.

OXLEY, Joanne E. Appropriability hazards and governance in strategic alliances: a transaction cost approach. Journal of Law, Economics, and Organization, v. 13, n. 2, p. 387-409, 1997.

PARKHE, Arvind. Partner nationality and the structure-performance relationship in strategic alliances. Organization Science, v. 4, n. 2, p. 301-324, 1993.

POWELL, Walter W. Expanding the scope of institutional analysis. In: POWELL, Walter W.; DIMAGGIO, Paul J. (Ed.). The new institutionalism in organizational analysis. Chicago: University of Chicago Press, 1991. p. 183-203.

PROVAN, Keith G.; KENIS, Patrick. Modes of network governance: structure, management and effectiveness. Journal of Public Administration Research and Theory, v. 18, n. 2, p. 229-252, 2007.

RING, Peter S.; VAN de VEN, Andrew H. Structuring cooperative relationships between organizations. Strategic Management Journal, v. 13, n. 17, p. 483-498, 1992.

ROTH, Ana L. et al. Diferenças e inter-relações dos conceitos de governança e gestão de redes interorganizacionais: contribuições para o campo de estudos. In: ENCONTRO NACIONAL DA ASSOCIAÇÃO DOS PROGRAMAS DE PÓS-GRADUAÇÃO EM ADMINISTRAÇÃO, 34., 2010, Rio de Janeiro. Anais... Rio de Janeiro: ANPAD, 2010.

SCOTT, William R. Institutions and organizations: ideas and interests. Thousand Oaks: Sage Publications, 2008.

SCOTT, William R. Symbols and organizations: from Barnard to the institutionalists. In: WILLIAMSON, Oliver E. (Ed). Organization theory: from Chester Barnard to the present and beyond. Nova York: Oxford University Press, 1995. p. 38-55.

SCOTT, William R. The adolescence of institutional theory. Administrative Science Quarterly, v. 32, n. 4, p. 493-511, 1987.

SCOTT, William R. The organization of environments: network, cultural, and historical elements. In: MEYER, John W.; SCOTT, William R. (Ed.). Organizational environments: ritual and rationality. Londres: Sage Publications, 1992.

SCOTT, William R.; MEYER, John W. The organization of societal sectors: propositions and early evidence. In: POWELL, Walter W.; DiMAGGIO, Paul J. (Ed.). The new institutionalism in organizational analysis. Chicago: University of Chicago Press, 1991. p. 108-140. 
WEGNER, Douglas. Governança, gestão e capital social em redes horizontais de empresas: uma análise das relações com o desempenho das empresas participantes. Tese (doutorado em administração) — Universidade Federal do Rio Grande do Sul, Porto Alegre, 2011.

WHETTEN, David A.; LEUNG, Thomas K. The instrumental value of interorganizational relations: antecedents and consequences of linkage formation. Academy of Management Journal, v. 22, n. 2, p. 325-344, 1979.

YIN, Robert K. Estudo de caso: planejamento e métodos. Porto Alegre: Bookman, 2001.

Marcos de Castro é doutor em administração pela Universidade Federal do Paraná (UFPR). Professor adjunto da Universidade Estadual do Centro-Oeste (PR). E-mail: marcosdecastroms@yahoo.com.br.

Sandro Aparecido Gonçalves é doutor em administração pela Fundação Getulio Vargas (FGV). Professor adjunto da Universidade Federal do Paraná (UFPR). E-mail: sag2@uol.com.br. 